\title{
Longitudinal Study of Blood Pressure during 8 Years; Patterns and Correlates: Yazd Healthy Heart Project
}

Namayandeh Seyedeh Mahdieh ${ }^{1}$, Rezaianzadeh Abbas ${ }^{2}$, Rajaeifard Abdoreza ${ }^{2}$, Tabatabee Hamidreza ${ }^{2}$ and Sadr Seyed Mahmood $^{1}$

${ }^{1}$ Yazd Cardiovascular Research Center and Clinic, Afshar Hospital, Shahid Sadoughi University of Medical Sciences, Yazd, Iran

${ }^{2}$ Epidemiology Department, School of Public Health, Shiraz University of Medical Sciences, Shiraz, Iran

"Corresponding author: Rezaianzadeh Abbas, MD, PhD, Epidemiology Department, School of Public Health, Shiraz University of Medical Sciences, Shiraz, Iran, Tel: 07117251001; E-mail: rezaiana@gmail.com

Received: December 30, 2015, Accepted: February 20, 2016, Published: February 29, 2016

Copyright: ( $) 2016$ Mahdieh SN, et al. This is an open-access article distributed under the terms of the Creative Commons Attribution License, which permits unrestricted use, distribution and reproduction in any medium, provided the original author and source are credited.

\begin{abstract}
Introduction: Hypertension (HT) is a prevalent contributor to cardiovascular diseases. To evaluate the incidence of HT and its relationship with other cardio metabolic risk factors changes and lifestyle components, Healthy Heart Project follow up data for 8 years were analyzed.
\end{abstract}

Methods: A total of 283 unique normotensive participants of Yazd Healthy Heart Project (1169 observations) attended blood pressure longitudinal study. Multi-level model and Generalized estimation equation (GEE) model with an unstructured correlation matrix were used to analyze the longitudinal data by Stata/MP 11.2.

Results: The incidence rates of HT and prehypertension were 39.5 and 77.93 in each 1000 person-year followup, respectively. In addition, systolic blood pressure was significantly predicted by diastolic blood pressure $(B=1.09$, $95 \% \mathrm{Cl}=0.99-1.19, \mathrm{P}<0.0001)$, uric acid $(\mathrm{B}=1.04, \mathrm{P}=0.003)$, and waist circumference $(\mathrm{B}=0.131, \mathrm{P}=0.033)$. Moreover, GEE model with logit link function showed that hypertension was significantly predicted by triglyceride $(O R=1.003$, $P=0.044)$, cholesterol $(O R=0.97, P=0.004)$, $L D L$-cholesterol $(O R=1.02, P=0.003)$, uric acid $(O R=1.19, P=0.023)$, body mass index $(O R=1.09, P=0.028)$, and also significantly predicted by obesity $(B=1.85, P=0.007)$, abdominal obesity $(B=1.85, P=0.007)$, age $(B=1.47, P=0.017)$, and diabetes mellitus $(B=2.14, P=0.003)$.

Conclusion: The study results showed that the incidence rate of HT was high in Yazd and the major predictors of systolic blood pressure were abdominal obesity and diastolic blood pressure. Besides, diastolic blood pressure was significantly determined by systolic blood pressure and general obesity. Moreover, both systolic and diastolic blood pressures were independently predicted by serum uric acid level.

Keywords: Longitudinal; Hypertension; Systolic blood pressure; Diastolic blood pressure; Yazd; Predictors

\section{Background}

Hypertension is a prevalent contributor to cardiovascular diseases. It is now a major public health problem affecting 1 billion individuals worldwide [1-3].

One single blood pressure (BP) measurement has a predictive value for future blood pressures given that many individuals remain normotensive. Medical Research Council (MRC) trial showed that $12-15 \%$ of the patients with diastolic blood pressure of at least 90 mmHg developed HT within 3-5 years [4,5]. The age- and sexadjusted incidence rate of HT varies in different populations. For instance, it has been reported as 12.75 per 1000 person-years adults in Chinese population and 25.5 per 1000 person-years among Canadians. Researchers have predicted a $24 \%$ increase in the prevalence of hypertension in developed countries from 2000-2025 [6,7].

In general, baseline age, high income levels, prehypertension, overweight, obesity, family history of hypertension, and low physical activity have been mentioned as the independent predictors of incident hypertension [7].
Investigators reported that age-related increases in BP are not exclusively increases with age rising and some other factors may be responsible [2].

Longitudinal studies can detect individual development of hypertension over time, the relationship between different variables and incident hypertension and longitudinal blood pressure changes [4].

The knowledge of blood pressure tracking may be useful for delaying age related increases in BP and development of systolic hypertension in older individuals [2]. To evaluate the pattern of blood pressure tracking and its relationship with changes in other cardio metabolic risk factors and lifestyle, we analyzed Healthy Heart Project follow-up data during 8 years.

\section{Methods}

\section{Study sample}

Phase I of Healthy Heart Project included assessment of the prevalence of cardiovascular diseases (CVD) risk factors in Yazd urban population, a city in center of Iran, in 2005. 
Page 2 of 6

The participants of this project were enrolled in a cohort study and underwent annual examination of CVD risk factors. Afterwards, 283 unique normotensive participants (1169 observations) attended blood pressure longitudinal study. Yet, 9 participants died from March 2005 up to October 2013 ( $\mathrm{n}=7$ dead due to cardiovascular causes). The study protocols for all the examinations were approved by the Institutional Review Board of Shahid Sadooghi University of Medical sciences. Besides, written informed consents were obtained from all the attendees at each examination.

\section{Clinical assessment}

Blood pressure was assessed at each examination using mercury sphygmomanometer based on the standardized protocol [8]. Accordingly, the first and five Kortokof sounds were considered as systolic and diastolic blood pressure, respectively and the means of the two measurements in each visit were recorded. In addition, pulse pressure was calculated as SBP-DPB and Mean Arterial Pressure (MAP) was calculated as $\mathrm{DBP}+(1 / 3 \mathrm{PP})$ or $2 \mathrm{DBP}+\mathrm{ABP}$. In case the two measurements were different by more than $20 \mathrm{mmHg}$, the third measurement was performed. Hypertension was defined as SBP $\geq 140$ $\mathrm{mmHg}$ or $\mathrm{DBP} \geq 90 \mathrm{mmHg}$ or taking antihy-pertensive therapy. Besides, diabetes mellitus was defined as fasting blood glucose $\geq 126$ $\mathrm{mg} / \mathrm{dL}$ or use of hypoglycemic medications. Moreover, hypercholesterolemia was defined as serum cholesterol $\geq 200 \mathrm{mg} / \mathrm{dl}$ and hyper-triglyceridemia was defined as serum triglyceride $\geq 150 \mathrm{mg} / \mathrm{dl}$ or use of lipid lowering medications.

\section{Statistical analysis}

The longitudinal design measures more than two times at multiple level: at individuals (between subject) and at different times (within subject). In this study, multilevel model was used to analyze the data. In general, multilevel models are used to evaluate the effect of clinical covariates on the pattern of blood pressure changes. Multilevel models can include and analyze maximal number of observations in a longitudinal study.

We used generalized estimation equation (GEE) model with an unstructured correlation matrix. Random intercept and random effects of age were used to reflect different starts and different slopes of each blood pressure for each participant. Then, a pre-specified model was fitted based on biologically plausible clinical and paraclinical covariate and blood pressure.

Blood pressure and its pathophysiological predictors were measured at unequal times $(1,2,3,4,5$, and 8 years after phase I of Yazd Healthy Heart Project). All the analyses were performed using Stata/MP, version 11.2 and 2-tailed P-value $<0.05$ was considered as statistically significant.

\section{Results}

The baseline and final measurements of the study sample have been shown in Tables 1 and 2. Measurements of BP and other metabolic measures were collected from a total of 1169 observations over 8 years of follow-up. The results indicated that most of the cardiometabolic factors were more prevalent at the end of the study compared to the first measurement.

\begin{tabular}{|l|l|l|l|}
\hline & Number & Percent & S.E \\
\hline Sex (male) & 170 & 60.1 & 0.026 \\
\hline
\end{tabular}

\begin{tabular}{|c|c|c|c|}
\hline Impaired Fasting Glucose & 5 & 1.8 & 0.007 \\
\hline Impaired glucose tolerance test & 33 & 11.7 & 0.019 \\
\hline Diabetes mellitus & 31 & 11 & 0.018 \\
\hline Cholesterol $>240 \mathrm{mg} / \mathrm{dl}$ & 42 & 14.8 & 0.021 \\
\hline Cholesterol $>200 \mathrm{mg} / \mathrm{dl}$ & 123 & 43.5 & 0.029 \\
\hline Triglyceride $>150 \mathrm{mg} / \mathrm{dl}$ & 135 & 47.7 & 0.029 \\
\hline Cholesterol/HDL >4 & 58 & 18.7 & 0.027 \\
\hline LDL Cholesterol >160 & 25 & 8.9 & 0.017 \\
\hline $\begin{array}{l}\text { HDL Cholesterol }>40 \text { in men-LDL Cholesterol } \\
<50 \text { in women }\end{array}$ & 83 & 29.3 & 0.029 \\
\hline $\mathrm{BMI}>30$ & 37 & 13.2 & 0.02 \\
\hline Waist $>88 \mathrm{~cm}$ in women, $>102 \mathrm{~cm}$ in men & 73 & 25.8 & 0.026 \\
\hline $25<\mathrm{BMI}<30$ & 116 & 41 & 0.029 \\
\hline Metabolic Syndrome & 68 & 24 & 0.025 \\
\hline Hyperuricemia ( $75 \%$ percentile) & 56 & 19.8 & 0.023 \\
\hline Smoking & 34 & 12 & 0.019 \\
\hline Passive smoking & 39 & 13.8 & 0.02 \\
\hline Typical Angina Pectoris rose score $\geq 3$ ) & 39 & 13.8 & 0.027 \\
\hline
\end{tabular}

Table 1: The demographic and clinical characteristics of participants in baseline measurement.

\begin{tabular}{|l|l|l|l|l|l|l|}
\hline \multicolumn{5}{|c|}{ Baseline characteristics based on sex } \\
\hline & \multicolumn{2}{|c|}{ Last measurement } & \multicolumn{2}{c|}{ First measurement } \\
\cline { 2 - 7 } & P value & $\begin{array}{l}\text { Women } \\
(\mathbf{1 1 3 )}\end{array}$ & $\begin{array}{l}\text { Men } \\
\mathbf{( 1 7 0 )}\end{array}$ & P value & $\begin{array}{l}\text { Women } \\
(\mathbf{1 1 3})\end{array}$ & $\begin{array}{l}\text { Men } \\
\mathbf{( 1 7 0 )}\end{array}$ \\
\hline $\begin{array}{l}\text { Impaired fasting } \\
\text { glucose }\end{array}$ & 0.18 & 23.3 & 30 & 0.66 & 1.8 & 1.8 \\
\hline $\begin{array}{l}\text { Impaired } \\
\text { glucose } \\
\text { tolerance test }\end{array}$ & 0.02 & 7.9 & $1 *$ & 0.55 & 11.5 & 11.8 \\
\hline $\begin{array}{l}\text { Diabetes } \\
\text { mellitus }\end{array}$ & 0.37 & 20.7 & 29.11 & 0.13 & 8 & 12.9 \\
\hline $\begin{array}{l}\text { Cholesterol>240 } \\
\text { mg/dl }\end{array}$ & 0.33 & 19.3 & 16.1 & 0.53 & 15 & 14.7 \\
\hline $\begin{array}{l}\text { Cholesterol } \\
>200 \text { mg/dl }\end{array}$ & 0.37 & 44.3 & 47.6 & 0.18 & 39.8 & 45.9 \\
\hline $\begin{array}{l}\text { Triglyceride } \\
>150 \text { mg/dl }\end{array}$ & 0.31 & 43.2 & 47.6 & 0.2 & 44.3 & 50 \\
\hline $\begin{array}{l}\text { Cholesterol/HDL } \\
>5\end{array}$ & 0.11 & 34.4 & 65.6 & 0.2 & 15.9 & 20.6 \\
\hline $\begin{array}{l}\text { LDL-cholesterol } \\
>160 \text { mg/dl }\end{array}$ & 0.38 & 18.3 & 15.7 & 0.28 & 7.3 & 10 \\
\hline $\begin{array}{l}\text { HDL Cholesterol } \\
>40 \text { in men-LDL }\end{array}$ & 0.0001 & 60.2 & 37.9 & 0.0001 & 45.6 & 18.8 \\
\hline
\end{tabular}


Citation: $\quad$ Abbas R, Mahdieh NS, Abdoreza R, Hamidreza T, Mahmood SS (2016) Longitudinal Study of Blood Pressure during 8 Years; Patterns and Correlates: Yazd Healthy Heart Project. J Hypertens 5: 215. doi:10.4172/2167-1095.1000215

Page 3 of 6

\begin{tabular}{|l|l|l|l|l|l|l|}
\hline $\begin{array}{l}\text { Cholesterol <50 } \\
\text { in women }\end{array}$ & & & & & & \\
\hline (BMI >30) & 0.011 & 29.3 & 15.5 & 0.02 & 18.8 & 9.5 \\
\hline $\begin{array}{l}\text { (Waist) >88 cm } \\
\text { in women, }>102 \\
\text { cm in men }\end{array}$ & 0.001 & 69 & 45.3 & 0.001 & 36.3 & 18.8 \\
\hline 25<BMl <30 & 0.42 & 46.7 & 41.1 & 0.1 & 46 & 37.6 \\
\hline $\begin{array}{l}\text { Hyperuricemia } \\
\text { (75\% percentile) }\end{array}$ & 0.44 & 27.7 & $2 \mathrm{~s} 5.8$ & 0.39 & 18.6 & 20.6 \\
\hline $\begin{array}{l}\text { Smoking } \\
\text { Passive smoking }\end{array}$ & 0.19 & 15.6 & 21.1 & 0.06 & 8 & 14.7 \\
\hline $\begin{array}{l}\text { Typical Angina } \\
\text { Pectoris rose } \\
\text { score } \geq 3 \text { ) }\end{array}$ & 0.43 & 17.6 & 19.5 & 0.09 & 37.2 & 28.8 \\
\hline
\end{tabular}

\begin{tabular}{|l|l|l|l|l|l|l|}
\hline Time & -2.36 & 0.56 & -4.18 & 0 & -3.47 & -1.25 \\
\hline Time*age & 0.05 & 0.01 & 4.23 & 0 & 0.02 & 0.07 \\
\hline cons & 17.82 & 5.9 & 3.02 & 0 & 6.25 & 29.38 \\
\hline
\end{tabular}

Table 3: Systolic blood pressure prediction by GEE populationaveraged model.

Table 4 depicts the diastolic blood pressure predictors by GEE model with identity link function.

\begin{tabular}{|l|l|l|l|l|l|l|}
\hline $\begin{array}{l}\text { Diastolic Blood } \\
\text { Pressure }\end{array}$ & Coef. & $\begin{array}{l}\text { Std. } \\
\text { Err. }\end{array}$ & $\mathbf{z}$ & $\mathbf{P}>|\mathbf{z}|$ & $\begin{array}{l}{[95 \%} \\
\text { Conf.] }\end{array}$ & $\begin{array}{l}\text { [Interv } \\
\text { al] }\end{array}$ \\
\hline Systolic blood pressure & 0.437 & 0.019 & 22.45 & 0 & 0.399 & 0.476 \\
\hline sex & -0.954 & 0.593 & -1.61 & $\begin{array}{l}0.10 \\
7\end{array}$ & -2.116 & 0.207 \\
\hline age & 0.012 & 0.037 & 0.33 & $\begin{array}{l}0.74 \\
1\end{array}$ & -0.061 & 0.085 \\
\hline waist & 0.057 & 0.026 & 2.19 & $\begin{array}{l}0.02 \\
9\end{array}$ & 0.006 & 0.108 \\
\hline Uric Acid & -0.089 & 0.212 & -0.42 & $\begin{array}{l}0.67 \\
6\end{array}$ & -0.504 & 0.327 \\
\hline Teriglyceride & 0.003 & 0.003 & 0.74 & $\begin{array}{l}0.45 \\
9\end{array}$ & -0.004 & 0.009 \\
\hline LDL-cholesterol & -0.001 & 0.004 & -0.34 & $\begin{array}{l}0.73 \\
7\end{array}$ & -0.01 & 0.007 \\
\hline HDL-cholesterol & 0.04 & 0.022 & 1.84 & $\begin{array}{l}0.06 \\
6\end{array}$ & -0.003 & 0.082 \\
\hline Fasting blood glucose & -0.003 & 0.01 & -0.32 & $\begin{array}{l}0.74 \\
6\end{array}$ & -0.023 & 0.016 \\
\hline time & 0.938 & 0.384 & 2.44 & $\begin{array}{l}0.01 \\
4\end{array}$ & 0.186 & 1.69 \\
\hline Time age interaction & -0.024 & 0.007 & -3.35 & $\begin{array}{l}0.00 \\
1\end{array}$ & -0.039 & -0.01 \\
\hline cons & 20.932 & 3.414 & 6.13 & 0 & 14.241 & 27.623 \\
\hline
\end{tabular}

Table 4: Diastolic blood pressure prediction by GEE populationaveraged model.

The GEE model with logit link function revealed that hypertension was significantly predicted by triglyceride $(\mathrm{OR}=1.003,95 \%$ $\mathrm{CI}=1.0001-1.006, \mathrm{P}=0.044)$, cholesterol $(\mathrm{OR}=0.97,95 \% \mathrm{CI}=0.96-0.99$, $\mathrm{P}=0.004)$, LDL-cholesterol ( $\mathrm{OR}=1.02,95 \% \mathrm{CI}=1.007-1.03, \mathrm{P}=0.003)$, uric acid $(\mathrm{OR}=1.19,95 \% \mathrm{CI}=1.02-1.39, \mathrm{P}=0.023)$, body mass index $(\mathrm{OR}=1.09, \quad 95 \% \mathrm{CI}=1.02-1.17, \quad \mathrm{P}=0.028)$, and also significantly predicted by obesity $(\mathrm{B}=1.85,95 \% \mathrm{CI}=1.18-2.88, \mathrm{P}=0.007)$, abdominal obesity $(\mathrm{B}=1.85,95 \% \mathrm{CI}=1.18-2.88, \mathrm{P}=0.007)$, age $(\mathrm{B}=1.47,95 \%$ $\mathrm{CI}=1.07-2.02, \mathrm{P}=0.017)$, diabetes mellitus $(\mathrm{B}=2.14,95 \% \mathrm{CI}=1.3-3.25$, $\mathrm{P}=0.003$ ) (Table 5).

\begin{tabular}{|l|l|l|l|l|l|l|}
\hline & $\begin{array}{l}\text { Odd } \\
\text { s } \\
\text { Rati } \\
\mathbf{0}\end{array}$ & $\begin{array}{l}\text { Std. } \\
\text { Hypertension }\end{array}$ & $\mathbf{z}$ & $\mathbf{P}>|\mathbf{z}|$ & $\mathbf{9 5 \%}$ Conf. & Interval \\
\hline sex & 0.69 & 0.16 & -1.62 & 0.1 & 0.45 & 1.08 \\
\hline
\end{tabular}




\begin{tabular}{|l|l|l|l|l|l|l|}
\hline Age & 1.01 & 0.01 & 0.45 & 0.65 & 0.98 & 1.03 \\
\hline $\begin{array}{l}\text { Fasting Blood } \\
\text { Sugar }\end{array}$ & 1 & 0 & 1.21 & 0.23 & 1 & 1.01 \\
\hline Triglyceride & 1 & 0 & 2.01 & 0.04 & 1 & 1.01 \\
\hline Cholesterol & 0.98 & 0.01 & -2.87 & 0 & 0.96 & 0.99 \\
\hline LDL-Cholesterol & 1.02 & 0.01 & 2.95 & 0 & 1.01 & 1.04 \\
\hline HDL-Cholesterol & 1.02 & 0.01 & 1.64 & 0.1 & 1 & 1.03 \\
\hline Uric Acid & 1.2 & 0.09 & 2.28 & 0.02 & 1.03 & 1.4 \\
\hline waist & 1.02 & 0.01 & 1.5 & 0.14 & 0.99 & 1.05 \\
\hline Body Mass Index & 1.09 & 0.04 & 2.2 & 0.03 & 1.01 & 1.18 \\
\hline Time & 0.81 & 0.1 & -1.73 & 0.08 & 0.64 & 1.03 \\
\hline Time*age & 1 & 0 & 0.87 & 0.39 & 1 & 1.01 \\
\hline
\end{tabular}

had referred in first year after the initial phase and did not have the history of hypertension. The incidence rate of hypertension in Yazd, the center of Iran, was almost 2 folds and 12\% higher than that among Chinese and Canadians, respectively. This can be due to the high prevalence of metabolic risk factors, such as obesity, particularly abdominal obesity, and diabetes mellitus, in our population [10].

In the study by Framingham, 458 out of the 3329 participants (13.8\%) developed hypertension at the 4 th year of follow up. In addition, age- and sex-adjusted incidence rates of hypertension increased progressively from $9.8 \%$ in the lowest quartile to $15.6 \%$ in the highest quartile of serum uric acid. Besides, the progression rate of BP increased from $32.8 \%$ (lowest quartile) to $39.6 \%$ (highest quartile) [11]. This rate is equal to 34.2 per 1000 person year and is almost similar to our study findings. Unfortunately, the present study researchers could find no publications about the incidence rate of hypertension in Iran, except for a study in Isfahan that reported the incidence rate of hypertension to be $542(22.1 \%)$ during 7 years of follow-up. That study revealed isolated systolic hypertension in 153 participants (28.2\%), increase in diastolic blood pressure alone in 92

Table 5: Hypertension prediction by GEE population-averaged model.

Furthermore, generalized linear mixed model by Stata/MP 11.2 showed that systolic blood pressure was predicted by diastolic blood pressure $(\mathrm{B}=1.1195 \% \mathrm{CI}=1.007-1.2 \mathrm{P}<0.0001)$, uric acid $(\mathrm{B}=0.8895 \%$ $\mathrm{CI}=0.24-1.5 \mathrm{P}<0.007)$, waist circumference $(\mathrm{B}=0.2695 \% \mathrm{CI}=0.13-0.38$ $\mathrm{P}<0.0001)$, and time $(\mathrm{B}=0.3195 \% \mathrm{CI}=0.016-0.61 \mathrm{P}=0.03)$ during 8 years.

\section{Discussion}

This study was a prospective analysis of Yazd Healthy Heart Project data. According to the results, the incidence rate of hypertension in our population was 39.5 in each 1000 person-year $(95 \% \mathrm{CI}=31.76-47)$ and that of prehypertension was 77.93 in 1000 person-years $(95 \%$ $\mathrm{CI}=63.43-92.43)$. In addition, the mean age at the onset of prehypertension was $50.5 \pm 2.1$ in males and $50.4 \pm 2.1$ in females, while that at the onset of prehypertension was $55.7 \pm 1.6$ in males and $55.9 \pm 1.6$ in females. Namayandeh et al. showed that the prevalence of hypertension was $25.6 \%$ in Yazd $(23.3 \%$ among females and $27.5 \%$ among males $(\mathrm{P}<0.001)$ [9].

World Health Organization (WHO) has predicted that the prevalence rate of hypertension will increase by $24 \%$ in developed countries from 2000-2025. Karen et al. reported that the age and sexadjusted incidence rate of hypertension increased from 25.5 per 1000 adults in 1997 to 32.1 per 1000 in 2004, showing a relative increase of $25.7 \%(\mathrm{P}<0.001)$ that could be attributed to obesity and sedentary lifestyle.

The age- and sex-adjusted prevalence rate of hypertension has increased by about $60.0 \%$ (from 153.1 per 1000 adults in 1995 to 244.8 per 1000 in 2005, $\mathrm{P}<0.001$ ) [6]. Sun et al. [7] evaluated the incidence of hypertension in China. After age adjustment, the incidence rate of hypertension was 12.75 per 100 person-years (95\% CI, 12.74-13.14) in males and 10.04 per 100 person-years (95\% CI, 9.69-10.41) in females. In normotensives, the incidence rate of hypertension was 11.08 per 100 person-years (95\% CI, 10.33-11.86) in males and 7.90 per 100 personyears $(95 \% \mathrm{CI}, 7.38-8.45)$ in females. Besides, the incidence rate of hypertension among the participants with prehypertension was 13.24 per 100 person-years (95\% CI, 12.79-13.69) in males and 11.22 per 100 person-years (95\% CI, 10.77-11.69) in females [7]. The present study was conducted on a subpopulation of Yazd Healthy Heart Project that participants $(17.0 \%)$, and both systolic hypertension and diastolic hypertension in 162 participants (29.9\%) [12]. One other study in Isfahan reported the incidence rate of hypertension among diabetic patients to be 20.8 per 100 person-years based on 9403 person-years of follow-up (20.6 among males and 20.9 among females) [13].

The results of the current study demonstrated that diastolic blood pressure, time, waist circumstance, and uric acid significantly predicted the increase in systolic blood pressure during 8 years. Besides, sex and age predicted blood pressure changes modestly.

Furthermore, diastolic blood pressure was significantly predicted by systolic blood pressure, time, and BMI. Moreover, GEE model with logit link function showed that hypertension was positively predicted by triglyceride, LDL cholesterol, uric acid, and BMI and negatively by cholesterol.

Generalized linear mixed model by Stata/MP 11.2 showed that systolic blood pressure was predicted by diastolic blood pressure $(\mathrm{B}=1.11 \quad 95 \% \quad \mathrm{CI}=1.007-1.2 \quad \mathrm{P}<0.0001)$, uric acid $(\mathrm{B}=0.88 \quad 95 \%$ $\mathrm{CI}=0.24-1.5 \mathrm{P}<0.007)$, waist circumference $(\mathrm{B}=0.2695 \% \mathrm{CI}=0.13-0.38$ $\mathrm{P}<0.0001)$, and time $(\mathrm{B}=0.3195 \% \mathrm{CI}=0.016-0.61 \quad \mathrm{P}=0.03)$ during 8 years.

Up to now, a number of important predictors of hypertension have been identified, including overweight/obesity, excessive dietary sodium intake, low physical activity, and smoking. A longitudinal study which was conducted on 5,296 female participants between 20 and 77 years of age in Dallas showed that even normal BMI, independent of other predictors, predicted hypertension development during 30 years of follow-up. However, the results revealed no significant relationship between waist circumference and hypertension development [14].

Increase in salt reabsorption by insulin in the distal nephron and hyperinsulinemic states have been shown to be associated with increased expression of renal $\mathrm{NaCl}$ cotransporter (NCC) [15]. Thus, increase in waist circumference resulting from insulin resistance can be associated with hypertension because of occurrence of hypervolemia due to salt reabsorption in this state.

Nonetheless, the pathophysiological mechanism by which higher BMI increases the risk of hypertension is not completely known. Complex interactions between metabolic and neurohormonal pathways, such as insulin resistance, renin-angiotensin-aldosterone 
system, and sympathetic tone, might be altered by increase in BMI Investigators have indicated decreases in plasma renin activity and plasma aldosterone levels after weight loss, also suggesting this association [14]. High fat diet leads to blood pressure elevation and induces renal sympathetic nerve activity (RSNA). This effect is mediated by central actions of leptin. In lower scale of the hypertension, insulin has central role but independent of RSNA [16]. Furthermore, duration of overweight plays a significant role in obesityrelated metabolic disorders, such as hypertension and diabetes mellitus $[17,18]$. In contrast, investigators have reported that there was no risk of hypertension development at a low diastolic blood pressure without weight gain. Borderline diastolic blood pressure $(85-95 \mathrm{mmHg})$ and obesity increase the risk of development of hypertension especially in men with the lower socioeconomic status.

In our study, waist circumference was significantly correlated with systolic blood pressure, hypertension development, and increase in BMI, but not with diastolic blood pressure. It has been thought that in comparison to diastolic blood pressure, systolic blood pressure was more significantly correlated to abdominal fat distribution and its underlying insulin resistance mechanism [5].

The association between serum uric acid and urine $\mathrm{pH}$ and metabolic syndrome has been evaluated in some studies. The association of a high serum uric acid and low urine $\mathrm{PH}$ with metabolic syndrome and hypertension has also been reported by other studies $[19,20]$. Additionally, a meta-analysis on a total of 18 prospective cohort studies $(55,607$ participants) showed that hyperuricemia was associated with an increased risk of new onset of hypertension (adjusted risk ratio $=1.41,95 \% \mathrm{CI}=1.23-1.58)$. These effects were significantly larger in young women [21].

The findings of the current study indicated that serum uric acid independently predicted systolic and diastolic blood pressure and hypertension development. A cross sectional study in Yazd also showed that age, total cholesterol, LDL-cholesterol, triglyceride, fasting blood glucose, impaired glucose tolerance test, body mass index, and waist circumference were significantly correlated to hypertension [9]. Some predictors of hypertension have been mentioned in various longitudinal studies. A cross sectional study in South-East Nigeria revealed that the mean total cholesterol, triglyceride, and LDLcholesterol were significantly higher in hypertensives and the mean HDL-C was comparable $(\mathrm{P}=0.8)$ [22].

Also, age [1,23], systolic and diastolic blood pressure level, smoking, family history of hypertension, diabetes mellitus [2], high body mass index [1], female sex, and lack of exercise were associated with development of hypertension [23]. Other investigators have found a negative association between smoking and incident hypertension $[1,2]$. Smoking cigarette acutely isncreased aortic stiffness and blood pressure in male subjects [24].

Moreover, serum cotinine levels, independent from other risk factors of cardiovascular diseases, were found to be associated with systolic blood pressure and hypertension in higher passive smokers [25].

In the studies conducted in USA between 1890 and 1990, in comparison to earlier cohorts, more recent cohorts had smaller increases in systolic blood pressure and their systolic blood pressure distributions were shifted lower as the age increased. The median systolic blood pressure decreases as $1.9 \mathrm{mmHg}$ in per decade translates into 11.4-13.3 mmHg over 6-7 decades [26].
In our study, time was negatively correlated to systolic blood pressure. This can be explained by the design effect. Besides, age had a positive but non significant correlation with systolic blood pressure.

\section{Study Limitations}

This study reevaluated the participants who were visited in the first year after baseline measurement. Thus, 283 participants were enrolled into this study. One of the limitations of the study was that heart rate measurement and glucose tolerance test were not performed in the first year and, consequently, we could not estimate heart rate changes and impaired glucose tolerance prediction value of hypertension.

\section{Suggestion}

The study can be followed for more years until all the participants experience outcome. Nonetheless, lifestyle is recommended to be evaluated for preventive intervention targets in future studies.

\section{Acknowledgment}

The authors would like to acknowledge Shiraz University of Medical Sciences and Yazd Cardiovascular Research Center for financially supporting the study. Professor Foruzannia SK is also appreciated for his cooperation and advices in conduct of the study. Thanks also go to Mrs. Sohela Lesan for participant invitation and data collection, Mrs. Ghahramani for assistance in thesis approval process, and personnel of cardiovascular research center and Afshar Hospital for participants' laboratory measurement and data entry.

Conflict of interest: None declared.

\section{References}

1. Wang W, Lee ET, Fabsitz RR, Devereux R, Best L, et al. (2006) A longitudinal study of hypertension risk factors and their relation to cardiovascular disease: the Strong Heart Study. Hypertension 47: 403-409.

2. Cheng S, Xanthakis V, Sullivan LM, Vasan RS (2012) Blood pressure tracking over the adult life course: patterns and correlates in the Framingham heart study. Hypertension 60: 1393-1399.

3. De Marco M, de Simone G, Roman MJ, Chinali M, Lee ET, et al. (2009) Cardiovascular and metabolic predictors of progression of prehypertension into hypertension: the Strong Heart Study. Hypertension 54: 974-980.

4. Jos WR (2003) Twisk Applied Longitudinal Data Analysis for Epidemiology A Practical Guide (2nd eds) Cambridge University Press, Netherlands.

5. Bakx JC, Van den Hoogen HJ, Van den Bosch WJ, Van Schayck C, van Ree JW, et al. (1999) Development of blood pressure and the incidence of hypertension in men and women over an 18-year period: results of the Nijmegen Cohort Study. J Clin Epidemio 52: 531-538.

6. Tu K, Chen Z, Lipscombe LL, Canadian Hypertension Education Program Outcomes Research T (2008) Prevalence and incidence of hypertension from 1995 to 2005: a population-based study. CMAJ 178: 1429-1435.

7. Sun Z, Zheng L, Detrano R, Zhang X, Xu C, et al. (2010) Incidence and predictors of hypertension among rural Chinese adults: results from Liaoning province. Ann Fam Med 8: 19-24.

8. Fava C, Sjögren M, Montagnana M, Danese E, Almgren P, et al. (2013) Prediction of blood pressure changes over time and incidence of hypertension by a genetic risk score in Swedes. Hypertension 61: 319-326.

9. Namayandeh S, Sadr S, Rafiei M, Modares-Mosadegh M, Rajaefard M (2011) Hypertension in Iranian urban population, epidemiology, awareness, treatment and control. Iran J Public Health 40: 63-70. 
Citation: $\quad$ Abbas R, Mahdieh NS, Abdoreza R, Hamidreza T, Mahmood SS (2016) Longitudinal Study of Blood Pressure during 8 Years; Patterns and Correlates: Yazd Healthy Heart Project. J Hypertens 5: 215. doi:10.4172/2167-1095.1000215

Page 6 of 6

10. Namayandeh S, Sadr S, Ansari Z, Rafiei M (2011) A Cross-sectional Study of the Prevalence of Coronary Artery Disease Traditional Risk Factors in Yazd urban population, Yazd Healthy Heart Project. Int Cardiovasc Res J 5: 7-13.

11. Sundström J, Sullivan L, D'Agostino RB, Levy D, Kannel WB, et al. (2005) Relations of serum uric acid to longitudinal blood pressure tracking and hypertension incidence. Hypertension 45: 28-33.

12. Talaei M, Sadeghi M, Mohammadifard N, Shokouh P, Oveisgharan S, et al. (2014) Incident hypertension and its predictors: the Isfahan Cohort Study. J Hypertens 32: 30-38.

13. Janghorbani M, Amini M (2005) Hypertension in type 2 diabetes mellitus in Isfahan, Iran: incidence and risk factors. Diabetes Res Clin Pract 70 71-80.

14. Shuger SL, Sui X, Church TS, Meriwether RA, Blair SN (2008) Body mass index as a predictor of hypertension incidence among initially healthy normotensive women. Am J Hypertens. 21: 613-619.

15. Chavez-Canales M, Arroyo JP, Ko B, Vazquez N, Bautista R, et al. (2013) Insulin increases the functional activity of the renal $\mathrm{NaCl}$ cotransporter. J Hypertens 31: 303-311.

16. Lim K, Burke SL, Head GA (2013) Obesity-related hypertension and the role of insulin and leptin in high-fat-fed rabbits. Hypertension 61: 628-634.

17. Janssen I, Katzmarzyk PT, Ross R (2004) Duration of overweight and metabolic health risk in American men and women. Ann Epidemiol 14 585-591.

18. Suglia SF, Clark CJ, Gary-Webb TL (2013) Adolescent obesity, change in weight status, and hypertension: racial/ethnic variations. Hypertension 61: 290-295.
19. Hara S, Tsuji H, Ohmoto Y, Amakawa K, Hsieh SD, et al. (2012) High serum uric acid level and low urine $\mathrm{pH}$ as predictors of metabolic syndrome: a retrospective cohort study in a Japanese urban population. Metab Clin Exp 61: 281-288.

20. Coutinho Tde A, Turner ST, Peyser PA, Bielak LF, Sheedy PF 2nd, et al. (2007) Associations of serum uric acid with markers of inflammation, metabolic syndrome, and subclinical coronary atherosclerosis. Am J Hypertens 20: 83-89.

21. Grayson PC, Kim SY, LaValley M, Choi HK (2011) Hyperuricemia and incident hypertension: a systematic review and meta-analysis. Arthritis Care Res (Hoboken) 63: 102-110.

22. Osuji CU, Omejua EG, Onwubuya EI, Ahaneku GI (2012) Serum lipid profile of newly diagnosed hypertensive patients in nnewi, South-East Nigeria. Int J Hypertens 2012: 710486.

23. Kshirsagar AV, Chiu YL, Bomback AS, August PA, Viera AJ, et al. (2010) A hypertension risk score for middle-aged and older adults. J Clin Hypertens (Greenwich) 12: 800-808.

24. Rhee MY, Na SH, Kim YK, Lee MM, Kim HY (2007) Acute effects of cigarette smoking on arterial stiffness and blood pressure in male smokers with hypertension. Am J Hypertens 20: 637-641.

25. Alshaarawy O, Xiao J, Shankar A (2013) Association of serum cotinine levels and hypertension in never smokers. Hypertension 61: 304-308.

26. Goff DC Jr, Gillespie C, Howard G, Labarthe DR (2012) Is the obesity epidemic reversing favorable trends in blood pressure? Evidence from cohorts born between 1890 and 1990 in the United States. Ann Epidemiol 22: 554-561. 